\title{
Article \\ Freight Operations Modelling for Urban Delivery and Pickup with Flexible Routing: Cluster Transport Modelling Incorporating Discrete-Event Simulation and GIS
}

\author{
Zichong Lyu ${ }^{1, * \mathbb{C}}$, Dirk Pons ${ }^{1, * \mathbb{D}}$, Yilei Zhang ${ }^{1}\left(\mathbb{D}\right.$ and Zuzhen $\mathrm{Ji}^{2}{ }^{\mathbb{D}}$ \\ 1 Department of Mechanical Engineering, University of Canterbury, Kirkwood Ave, \\ Christchurch 8140, New Zealand; yilei.zhang@canterbury.ac.nz \\ 2 Department of Chemical and Biological Engineering, Zhejiang University, Zheda Ave, \\ Hangzhou 310027, China; jizuzhen@zju.edu.cn \\ * Correspondence: zichong.lyu@pg.canterbury.ac.nz (Z.L.); dirk.pons@canterbury.ac.nz (D.P.); \\ Tel.: +64-21-084-99600 (Z.L.)
}

check for updates

Citation: Lyu, Z.; Pons, D.; Zhang, Y.; Ji, Z. Freight Operations Modelling for Urban Delivery and Pickup with Flexible Routing: Cluster Transport Modelling Incorporating Discrete-Event Simulation and GIS. Infrastructures 2021, 6, 180. https://doi.org/10.3390/ infrastructures6120180

Academic Editor: Maxim A. Dulebenets

Received: 11 November 2021 Accepted: 14 December 2021 Published: 17 December 2021

Publisher's Note: MDPI stays neutral with regard to jurisdictional claims in published maps and institutional affiliations.

Copyright: (c) 2021 by the authors. Licensee MDPI, Basel, Switzerland. This article is an open access article distributed under the terms and conditions of the Creative Commons Attribution (CC BY) license (https:// creativecommons.org/licenses/by/ $4.0 /)$.

\begin{abstract}
Urban pickup and delivery (PUD) activities are important for logistics operations. Real operations for general freight involve a high degree of complexity due to daily variability. Discreteevent simulation (DES) is a method that can mimic real operations and include stochastic parameters. However, realistic vehicle routing is difficult to build in DES models. The objective is to create a DES model for realistic freight routing, which considers the driver's routing decisions. Realistic models need to predict the delivery route (including time and distance) for variable consignment address and backhaul pickup. Geographic information systems (GIS) and DES were combined to develop freight PUD models. GIS was used to process geographical data. Two DES models were developed and compared. The first was a simple suburb model, and the second an intersection-based model. Real industrial data were applied including one-year consignment data and global positioning system (GPS) data. A case study of one delivery tour is shown, with results validated with actual GPS data. The DES results were also compared with conventional GIS models. The result shows the intersection-based model is adequate to mimic actual PUD routing. This work provides a method for combining GIS and DES to build freight operation models for urban PUD. This has the potential to help industry logistics practitioners better understand their current operations and experiment with different scenarios.
\end{abstract}

Keywords: freight delivery with backhaul pickup; discrete-event simulation; geographic information system; dynamic routing

\section{Introduction}

Freight transport is important for goods supply and the world economy. For New Zealand, which is the case under examination, freight transport is a major section for economic growth [1]. However, there are still difficulties in developing freight models [2-4]. In practice, freight companies have needs for improving the efficiency of operations [5]. General freight operations are complex because of the high degree of daily variability in consignments [6,7], and the need to match this to vehicle fleet composition [8], vehicle allocation and routing [9], shipment consolidation and dispatching [7], diverse types of infrastructure and network design [10]. Road transport is the primary mode in New Zealand, and industries are highly reliant on road transport in domestic distribution [11,12]. Compared with line-haul transport, there is more flexibility in short-haul transport regarding route selection, multiple destinations and traffic complexity. Mathematical models have been extensively applied to freight problems. However, mathematical techniques are insufficient to represent the real operations and randomness. Therefore, there is value in developing a freight logistics model more able to accommodate variability and randomness. 
Discrete event simulation (DES) has been widely used to simulate operations problems with stochastic events [13]. It can analyse the system at the consignment level. Analysis of roadway including road segments, travel speed and travel time can benefit transport modelling [14]. However, for freight transport, it is challenging to create the transportation network in DES. To mimic the real operations, the driver's decisions should be included in the model.

This paper describes a method for combining Geographic information system (GIS) and DES for modelling pickup and delivery (PUD) operations. GIS was applied to identify customer clusters, the transport network and route selections. The resulting model has partial flexible routing with a backhaul pickup. The model can reflect the driver's routing decisions in the route selection. Two freight simulation models were proposed, which are a simple suburb model and an intersection-based model. The result was validated with global positioning system (GPS) data and compared with conventional GIS models.

\section{Literature Review on Urban Pickup and Delivery with Flexible Routing}

\subsection{Conventional Vehicle Routing Problems (VPRs)}

PUD is also known as short-haul transport. Complexities arise from scattered and random customer locations, unpredictable demand and unexpected traffic conditions. Typical issues in transportation are Vehicle Routing Problems (VRPs). Explicit VRPs with explanations are shown in Table 1.

Table 1. Typical Vehicle Routing Problems.

\begin{tabular}{cr}
\hline Problems & Explanation \\
\hline Node routing problem (NRP) [15,16] & No need for arcs and edges \\
\hline Travelling salesman problem $[9,17,18]$ & $\begin{array}{c}\text { One circuit is finished by one vehicle in NRP, } \\
\text { Including the asymmetric travelling salesman problem and the } \\
\text { symmetric travelling salesman problem }\end{array}$ \\
\hline Arc routing problem (ARP) $[19-21]$ & No need for vertices \\
\hline Rural postman problem (RPP) [22,23] & One circuit finished by one vehicle in ARP \\
\hline Chinese postman problem (CPP) [24-26] & Each arc and edge needs to be serviced in RPP \\
\hline Real-time vehicle routing and dispatching problem [27-29] & $\begin{array}{c}\text { GIS, GPS, vehicle allocation could be involved. } \\
\text { Considerations include quick response, denied or deferred service, } \\
\text { congestion and system dynamism [7] }\end{array}$ \\
\hline
\end{tabular}

Models of VRPs are developed based on the concept of optimising the combination of travel time, tour cost and travel distance with elements of vertices, arcs and edges where vertices refer to addresses, and arcs (directed routes) and edges (undirected routes) refer to routes [7]. Constraints are generally added to these problems, such as vehicle capacity, time windows, customer priority, backhaul for pickups, and simultaneous delivery and pickup. VRPs are built by mathematical models, which primarily are mixed-integer linear programming models [23]. Mixed-integer linear programming is a mathematical optimisation method with objective functions and constraints, which was frequently conducted in transportation problems. The most well-known problem is the Travelling Salesman Problem (TSP). VRPs are NP-hard (nondeterministic polynomial time) problems, so these mathematical models can be solved by heuristic method [9] or metaheuristic method [22,29] including genetic algorithm $[17,18,26,27]$, tabu search, ant colony optimisation, simulated annealing, variable neighbourhood search, etc. [30].

The most significant advantage of mathematical models is they can be created and solved quickly. However, there are limitations in these models. In conventional mathematical models, the complexity of the calculation complicates the representation of randomness $[13,30]$. The randomness of freight transport can be freight volume, traffic conditions, or random customer addresses. In addition, these mathematical techniques simplify real 
systems, e.g., in analytical techniques, it is difficult to add sufficient path constraints and realistic scheduling of vehicles [31]. The simplification further leads to discrepancies in results. For example, driver's decisions are difficult to include. Also, the results of mathematical models are unable to reveal detailed processes of operations, so different operations scenarios are challenging to compare.

\subsection{GIS}

Geographic Information System (GIS) has been widely used to analyse geographic data, and it can also run routing simulations. Compared with pure mathematical models, a significant advantage of GIS is that geographical data is used to determine customer addresses, which means that distances are more accurately measured. In addition, software such as ArcGIS ${ }^{\circledR}$ has a database of road conditions and historic traffic information which improve the results for travel time and route selection. Applications of GIS in the VRP freight literature include freight system analysis [32], forest firefighting [33], waste collection routes [34-37] (the latter also including Artificial Neural Network (ANN)), truck configuration [34], emissions including carbon dioxide [38,39], and operation costs [40].

Although GIS is able to include various features, some necessary features need to be manipulated manually, and there can be inaccuracies in the data [41]. GIS is inconvenient to solve multiple routing cases since the input is deterministic. Moreover, GIS mainly focuses on the routing section rather than the holistic operations.

\subsection{Computer Simulation Methods}

Computer simulation methods for freight logistics primarily include Agent-based Simulation (ABS) and Discrete-event Simulation (DES). ABS allows individual entities to determine their own process whereas DES is more dedicated to system analysis with predefined system architecture.

Large literatures exist for ABS and DES. Selected examples for ABS, relevant to freight are supermarket freight distribution using ABS [42], TSP using ABS and Constructive Heuristics [43] or Particle Swarm Optimisation [44] to solve TSP, home hospital services using ABS and GIS [45]. However, ABS may be insufficient to describe detailed freight processes because it focuses on individual behaviour [46].

DES has been used to solve transport problems such as rail yard simulation [47], urban rail freight [48], passengers transport [49], multimodal transport [50], container port operations [51] real-time dispatching and fleet management [52], and freeway patrol service [53]. DES splits the whole process into separate processes into different time periods. In each time period, the entity is deemed to have the same status. In addition, instead of solving constraints altogether, DES splits the process into individual events and simulates events sequentially so it decreases the difficulty of multiple constraints. This attribute greatly decreases the computing time of DES so randomness is able to be involved via Monte Carlo methods.

DES is not a common method for solving VRPs. Applications include meal delivery with uncertain requests and couriers with fixed routes [54], location-routing via Ant Colony Optimisation (ACO) and DES [55], Rich Vehicle Routing Problems [56], pickup and delivery problems with energy consumption [57], and vehicle routing with multiple constraints [58].

\subsection{Gaps}

The complexity of real freight networks is challenging. Existing mathematical methods for freight routing modelling tend to include large simplifications in route constraints [13,31], leading to inaccuracy in results. In addition, driver's decisions are barely involved to predict the route. While GIS models may solve the routing problem, they do not address the holistic logistic operations, nor do they tolerate variability (except by manual methods). Although DES models could deal with randomness, current DES models are limited to represent the freight network in terms of road attributes, customer cluster analysis and 
freight operations. Furthermore, DES models lack historical information and data to suit the real operations and validation for routing.

Therefore, there is a potential benefit to develop a method that integrates GIS and DES to cope with intricate truck routes and variable customer locations, and involves practical methods for practitioners to understand and optimize their operations.

\section{Method}

\subsection{Research Objective}

The objective of the paper was to find a method to create a credible PUD model by using DES. The DES model should reflect the real operations with the driver's route selection. In addition, the method should not only provide solutions but also be suitable for practical industrial implementation. In discussion with the industry, it was identified that the main objective function from an operational perspective was time to complete the delivery tour, as this affects cost and service quality. In this paper, we do not seek to optimize delivery time or cost, but rather find ways to create models that could be used for such purposes in a general freight situation of high daily variability of consignments.

\subsection{Approach}

First, industrial data were obtained for one-year consignments and GPS data. Due to the consequence of COVID-19, consignment data for 2019 was used instead of the data for 2020. Consignment data were used from 2019, and used to analyse customer clusters. GPS data were unavailable for 2019, and instead used 2020 data. The GPS data were only used to investigate trucks routes and calculate speeds. Although 2020 represented COVID-19 operating conditions, it is believed that the overall road conditions, speeds and routes were representative. This is because GPS data was used for the whole year, and while there were COVID-19 lockdowns in New Zealand they were of short duration. Furthermore, the truck route was validated by checking with the driver and the dispatcher.

GIS analysis was conducted in ArcGIS pro ${ }^{\circledR}$. GPS data was imported in ArcGIS to identify truck historical locations. Consignment data were used to analyse customer clusters. Second, DES models were implemented in Arena ${ }^{\circledR}$. Despatchers and drivers were interviewed about their route decisions, and truck tour observations were conducted by the first author. Ethics approval was obtained (Reference: HEC 2020/65/LR-PS).

The overall design of the DES model included an operations part and a transport part. The operations part includes a DES model for consignment arrival and freight consolidation, which takes into account weight and volume relative to truck capacity. These results are not reported here. For the transport network, which is the focus of the current paper, the problem includes freight loading at the dock via forklift, travel to destination, unloading at destination, and regular backhaul pickup. Two DES models were devised for the transportation, with slightly different architectures. The first is called the Simple Suburb Model. It has the defining feature that suburbs are directly connected to nearby suburbs by distance parameters. The second model is called the Intersection Based Model. It is more complex as it includes major road intersections. This gives a greater ability to model the route specifics. In both cases, the overall architecture of the model consists of geographic centres of the suburbs represented as nodes in the model. Distances between suburbs are included, but the two models differ in how they accomplish this. The objective function was time to complete the delivery tour, and total distance travelled. Of these parameters, the time was more important from the client's operational perspective, because of the need to complete all deliveries within the day. However, from the perspective of emissions, e.g., tonne-kilometer, the distance is the more important. Input variables are speeds, route selection, distances between clusters/intersections, destination and number of consignments in the load. Average speeds for different types of roads were calculated based on GPS data. These speeds were applied to networks.

To construct the transport network, intersections and roads were explored regarding road selection and road conditions. This process was clarified by the truck driver and the 
dispatcher. The street view of Google maps ${ }^{\circledR}$ was used to identify road details, intersections, and identification of customer locations. In contrast, average speeds for truck routes were calculated by using GPS data, and GIS was used to determine routes using the TSP algorithm. Route selection and delivery sequence were validated with the industry client.

A summary of the combined GIS and DES simulation modelling approach is shown in Figure 1.

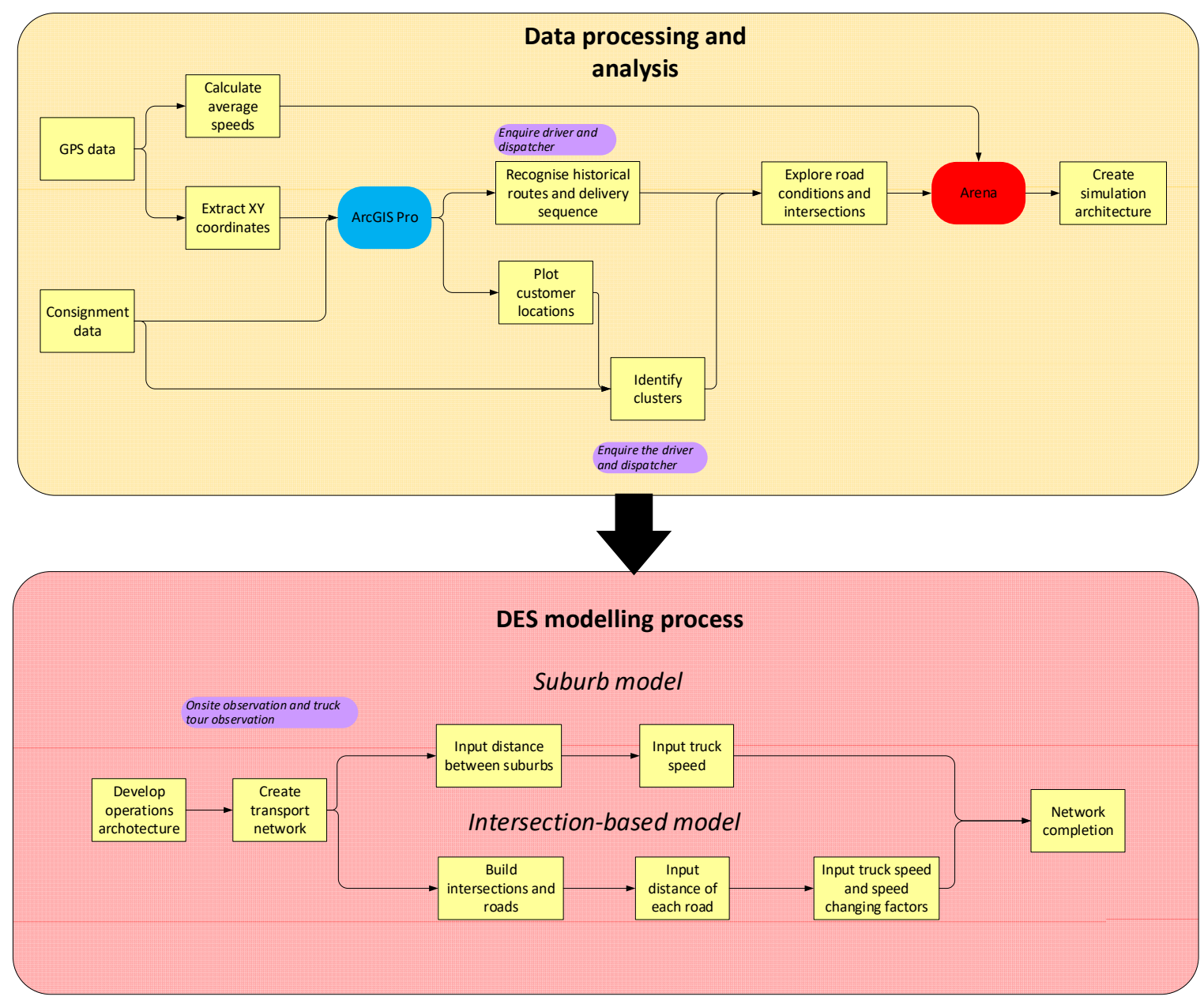

Figure 1. Workflow of combined GIS and DES simulation modelling approach.

\section{Results}

\subsection{Identification of Main Suburbs}

The truck mainly serves Less than Container Load (LCL) freight, which means multiple customer addresses are visited in one truck tour. Moreover, the truck undertakes various types of jobs including first-mile pickups, last-mile deliveries, and metro freight transport as separate tours. This study examines the delivery tours. These are finished in the morning with pick up freight in the backhaul.

The last-mile delivery consignments were consolidated in suburbs by a pivot table. To simplify the network, the low freight volume suburbs were abandoned. Some cleaning of the data was conducted. Some suburbs have rare deliveries, and it is impractical to develop a simulation model for all these outliers. The outlier threshold was $1 \%$ of consignment numbers. This is justified, because in discussion with the dispatcher, it transpired that in some cases these outliers were because the driver was helping other drivers. These outliers were excluded from further analysis. From this, the main suburbs were identified. Table 2 shows the one-year consignment data for the examined truck. 
Table 2. One-year consignment data for the truck. Data sourced from the industry partner.

\begin{tabular}{cc}
\hline Suburb & Percentage \\
\hline PAPANUI & $50.84 \%$ \\
BURNSIDE & $10.30 \%$ \\
CHRISTCHURCH AIRPORT & $7.88 \%$ \\
HAREWOOD & $7.53 \%$ \\
BISHOPDALE & $7.47 \%$ \\
ST ALBANS & $3.38 \%$ \\
YALDHURST & $3.06 \%$ \\
NORTHCOTE & $2.62 \%$ \\
AVONHEAD & $2.29 \%$ \\
NORTHLANDS & $1.88 \%$ \\
BRYNDWR & $0.44 \%$ \\
MAIREHAU & $0.38 \%$ \\
WIGRAM & $0.32 \%$ \\
CHRISTCHURCH CENTRAL & $0.32 \%$ \\
HORNBY & $0.24 \%$ \\
REDWOOD & $0.21 \%$ \\
RICHMOND & $0.21 \%$ \\
HALSWELL & $0.18 \%$ \\
SOCKBURN & $0.09 \%$ \\
RUSSLEY & $0.09 \%$ \\
ADDINGTON & $0.06 \%$ \\
STROWAN & $0.03 \%$ \\
FENDALTON & $0.03 \%$ \\
SYDENHAM & $0.03 \%$ \\
CHRISTCHURCH & $0.03 \%$ \\
BELFAST & $0.03 \%$ \\
MIDDLETON & $0.03 \%$ \\
ILAM & $0.03 \%$ \\
\hline
\end{tabular}

Customer locations and trucks GPS data were plotted in ArcGIS ${ }^{\circledR}$ as shown in a heat map, see Figure 2. This provided a visual check of consistency. It was noted that some suburbs were close together, so that the distinctions were artificial. These were lumped together, e.g., Papanui and Northcote. This part of the work also provided a visual representation of how tightly grouped the deliveries were in any one cluster. This is relevant because it potentially affects in-cluster deliveries. In the present case, the clusters were deemed to have similar density and hence a common in-cluster parameter was assumed throughout. GPS data include truck location with speed, and represents different types of roads.

This is a discrepancy between consignment data and GPS data. The GPS data in 2019 is unavailable so the GPS data in 2020 and 2021 were used instead. The company developed new customers after 2019 in the Mcleans Island suburb (in the west of the airport). However, it hardly affects the result of route selection and it has been checked with the dispatcher and the driver.

\subsection{Discrete-Event Simulation Model}

\subsubsection{Freight Operations Modelling}

DES simulation for freight operations are developed into two parts: operations and transport. Freight operations were considered as a series of discrete events. The status of freight consignments is identical in each process. Figure 3 illustrates the operations of freight delivery, and further modelled via Arena. 


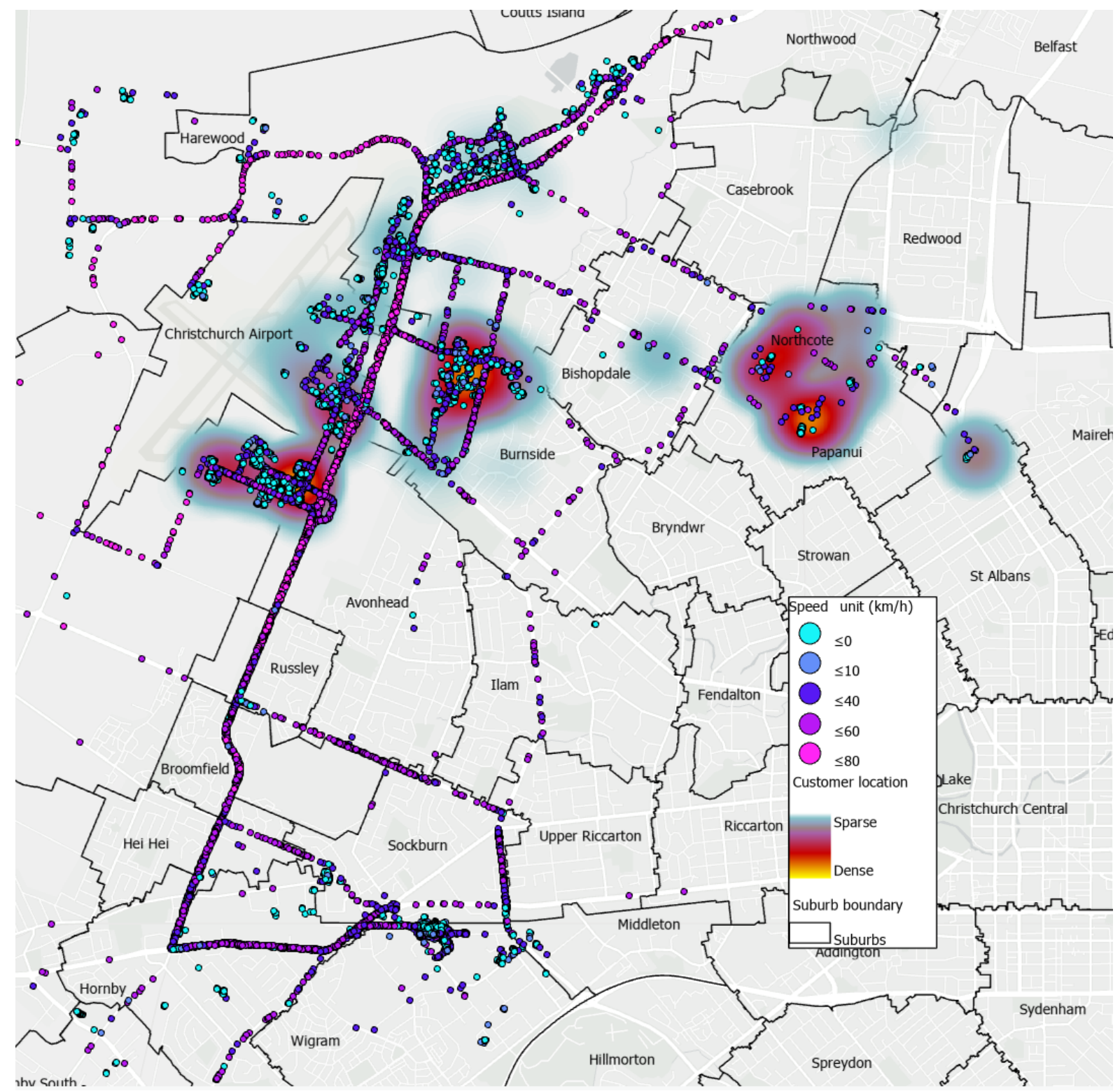

Figure 2. Dots show truck speeds recorded by GPS. Heat map shows customer locations with the number of consignments. GPS data from industry partner.

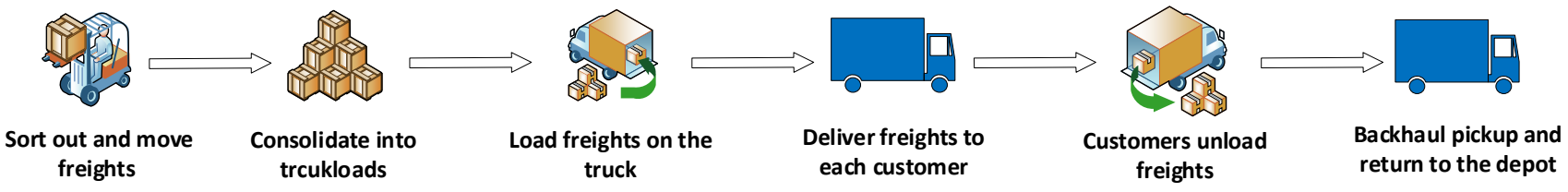

Figure 3. Freight delivery operations modelled by DES.

The driver drove a forklift to sort out the freight and load on the truck. Observation showed that the forklift usually carries one pallet of freight but sometimes multiple pallets. This operation was simplified as one loading process by a forklift with the capacity of one pallet. The truck limit is subject to freight weight and volume so these two parameters are included in the consolidation process. The unloading module has the same process in each cluster since most of the customers unload freight by themselves.

For backhaul, the driver is always assigned to finish a pickup in a warehouse. There are several reasons for conducting the pickup in the backhaul. For the pickup, the driver 
operates a forklift to load freights so this process can take about $30 \mathrm{~min}$. Moreover, if they pick up a larger number of pallets, it is more difficult to unload other freights.

\subsubsection{Transport Modelling}

The network in this study was created by distance with truck speeds. For route searching, the least-distance route is preferable.

The truck speed was recorded by GPS data and categorised into various roads. Distributions of speeds on different roads were determined; see Figure 4. The speed limit for open roads is $80 \mathrm{~km} / \mathrm{h}$, and for urban roads was considered as $60 \mathrm{~km} / \mathrm{h}$ because $50 \mathrm{~km} / \mathrm{h}$ and $60 \mathrm{~km} / \mathrm{h}$ are mixed on some roads. The GPS data were analysed to calculate average speeds. The $0 \mathrm{~km} / \mathrm{h}$ speed for loading and unloading was excluded so the data includes acceleration speed, deceleration speed, and the $0 \mathrm{~km} / \mathrm{h}$ speed for traffic lights and congestions on the road.

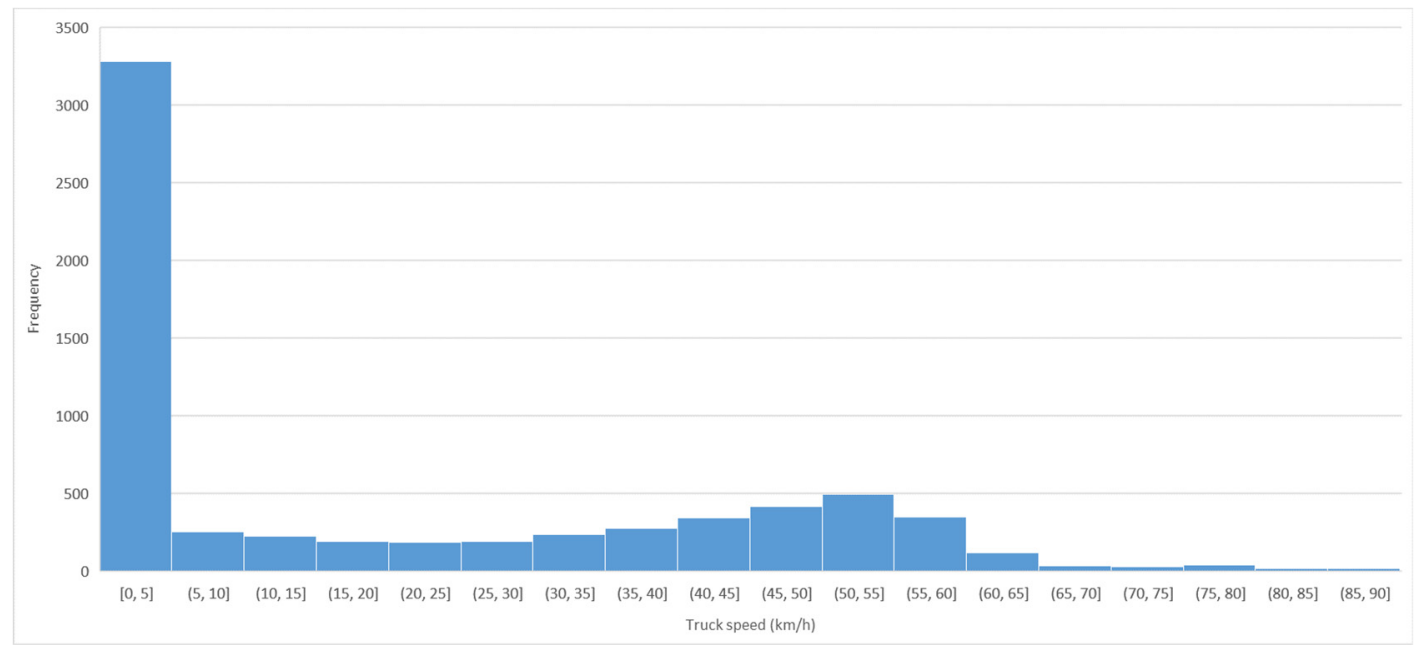

(a)

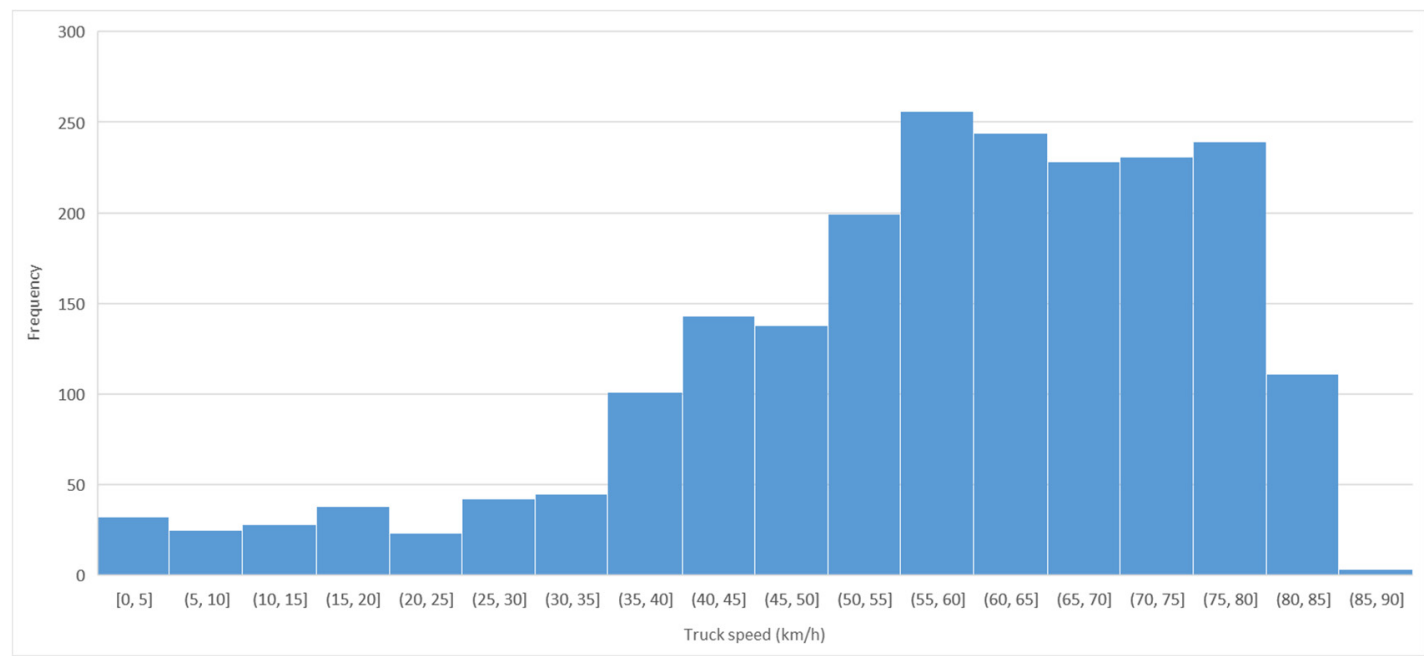

(b)

Figure 4. Distribution of truck speeds on (a) urban roads; (b) open roads within the city environment. Data from GPS from the truck.

The average speeds of the truck on the open road and the urban road were calculated; see Table 3. The delivery sequence was established according to the analysis of GPS data (as shown in Figure 2) and enquiry with the driver and the dispatcher; see Table 4. The reason that driver follows this sequence is mostly from the consideration of travel distance, 
and familiarity with customers and traffic. The driver preferred the open road because of quicker travel time.

Table 3. Truck average speeds on open road and urban road, from GPS data.

\begin{tabular}{cc}
\hline Road Type & Average Speed $(\mathbf{k m} / \mathbf{h})$ \\
\hline All roads & 30.633 \\
Open road & 56.140 \\
Urban road & 23.279 \\
\hline
\end{tabular}

Table 4. Truck delivery suburb sequence.

\begin{tabular}{cc}
\hline Sequence & Suburb Cluster \\
\hline 1 & Yaldhurst \\
2 & Christchurch airport \\
3 & Burnside \\
4 & Harewood \\
5 & Bishopdale \\
6 & Papanui \\
7 & ST Albans \\
8 & Backhaul pickup \\
\hline
\end{tabular}

\subsection{Simple Suburb Cluster Network with DES with an Average Speed}

For the transport network, two structures were developed. The first network consists of simplified suburb clusters and each cluster is connected directly with the centre of other clusters. Figure 5 illustrates the freight network of the simple suburb cluster model in Arena ${ }^{\circledR}$. Distances between cluster centres of suburbs were obtained from Google maps ${ }^{\circledR}$.

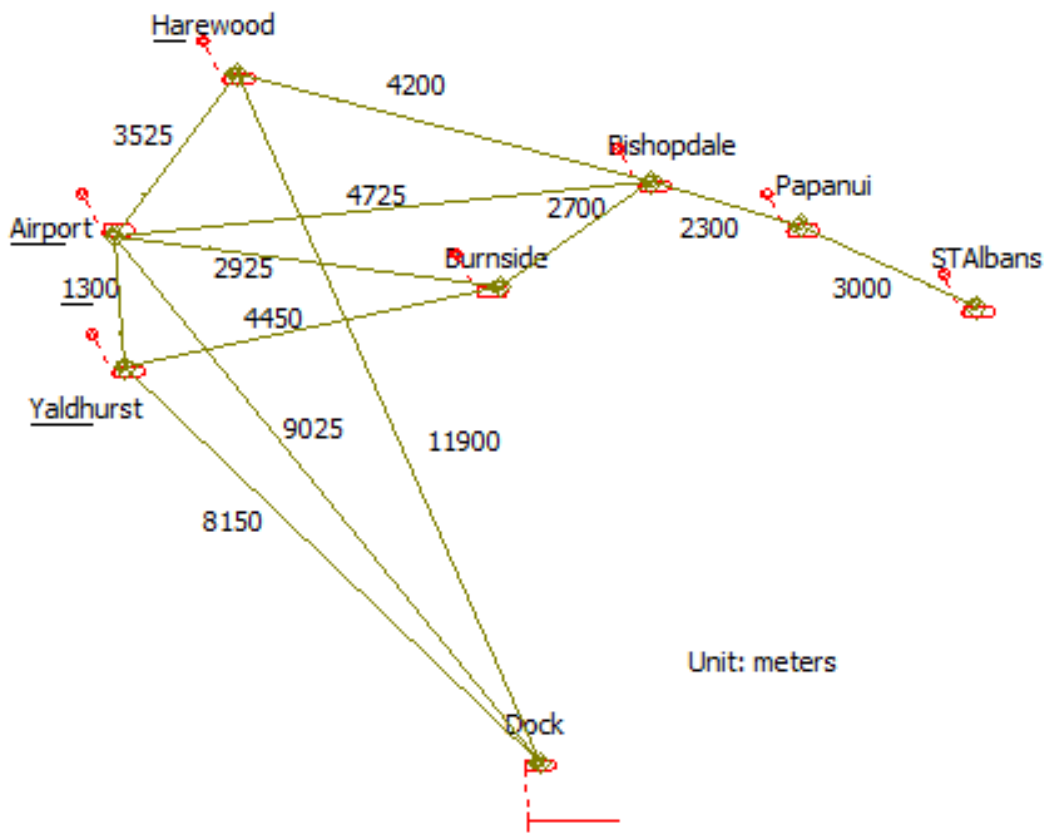

Figure 5. Transport network of simple suburb cluster model.

The priority of suburbs was set up consistent with the real delivery sequence. The model provides a sequence in which suburbs will be visited. This sequence resulted from GPS data analysis and enquiry for the truck driver and the dispatcher. Due to simplification of the network, the speed of the truck is assumed to be the average speed for all routes.

The simple suburb model shown above was to be generalised to a model that could basically reflect the delivery activity of the truck. There are some advantages of the simple 
suburb model. The simulation modelling time is short since the network is simplified and specific routes that the truck took were not needed to construct the network. Therefore, the simple suburb model can be quickly extended to a larger model such as a whole city model. This model might be used to quickly explore new markets or operational adjustments.

A limitation of the simple suburb network is that roads cannot be presented, which means the input relative to traffic are hard to determine, such as different truck speeds on open roads and urban roads. Besides, the route varies based on the set of destination clusters because the driver prefers open roads with a high-speed limit.

A more realistic model architecture would be based on major roads and driver's perceptions of the speed and ease of getting a large truck to a specific destination. The road perspective is natural to the driver, and it is also intrinsic to the way that GPS formulates the situation. While it is possible for DES to represent a network of roads, there is still the need to include travel time and other road-specific information. This is where GIS has the advantage since it has data on roads attributes (speed limits, congestion, intersection wait times, live traffic data, etc.) and it can already use this to determine an optimal route between two addresses. Discussion with drivers showed that they used similar considerations in determining their own route for the day's consignments.

To transfer information from GIS into DES it is advantageous to reformulate the architecture of the model as a network of road intersections as opposed to merely suburb centres.

\subsection{Intersection-Based Network with Specified Speeds}

The second freight network is the intersection-based network. Main clusters and intersections were identified in Figure 6. In making this decision, Google Maps ${ }^{\circledR}$ was applied to assist this process, and the distance between intersections was searched. Moreover, the satellite view and street view of Google Maps ${ }^{\circledR}$ were applied to explore road conditions including road directions and highway interchange traffic. For example, some intersections prohibit turning right or left. The truck needs to take another road or use the interchange to change the direction. The centre of each cluster represents the whole cluster so the distance between the centre and the nearest road intersection was measured.

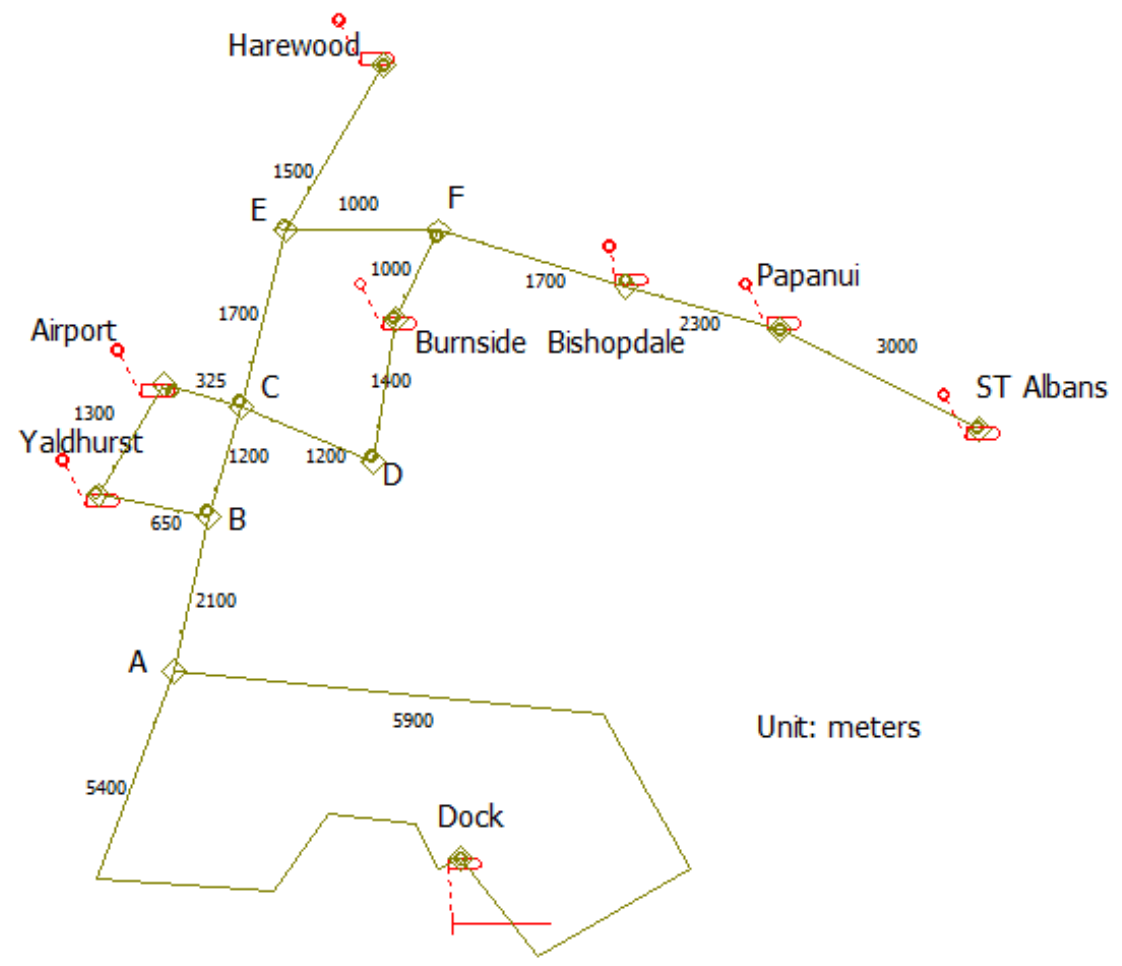

Figure 6. Freight network of the intersection-based model. 
The driver expressed a preference for the open road above urban roads. Besides, the turn-left time was also considered because turn-right normally costs more time, especially in traffic peak time.

Combining the above information lead to the design of an intersection-based freight model, and its construction in Arena ${ }^{\circledR}$. Figure 6 presents the freight network of the intersection-based model.

Two routes were modelled from the dock to intersection A. This comes from the driver' experience and historical GPS data (as shown in Figure 2). The driver chooses different routes for drive-out and drive-in because of the consideration of turn-right times and traffic conditions. However, this choice varies based on real-time traffic. In the model, these two routes were set as one-way routes. The travel sequence is from the closest cluster to the furthest cluster. That means the truck starts to drop off freight from the nearest customer. This process accords with the driver's routine. However, this sequence may be occasionally changed according to the real priority of freight in practice.

\subsection{Case Study}

\subsubsection{Description}

To validate the model, one delivery tour with a backhaul pickup of the truck was selected. There were 5 deliveries locations and 1 backhaul pickup location. Table 5 shows input delivery suburbs with consignment numbers for DES models. The backhaul pickup is located in Yaldhurst. The simulation was implemented in Arena ${ }^{\circledR}$.

Table 5. Delivery suburbs with consignment numbers in DES models.

\begin{tabular}{cc}
\hline Delivery Suburb & Consignment Number \\
\hline Airport & 1 \\
Harewood & 1 \\
Yaldhurst & 2 \\
Papanui & 2 \\
\hline
\end{tabular}

For large volume deliveries, the driver switched off the ignition of the truck while he parked the truck and finished the unloading activity. This shows up in the GPS data. For small parcels, the driver kept the engine on. Figure 7 presents delivery locations and corresponding routes based on GPS data. GPS data provides historical locations of the truck with time and $\mathrm{XY}$ coordinates, trip distance and actions operated by the driver to the truck. The data was imported to ArcGIS by XY coordinates. The GPS data were cleaned by extracting the travel segments, and ignoring the time spend on unloading/loading. This was achieved in two ways: (1) Engine on/off actions were recorded in the GPS logs, and these were used to identify the unloading/loading times for exclusion: (2) In some cases the driver did not switch the engine off at the delivery location, and these case were identified by the consignment note and examining when the truck was motionless. The frequency of GPS data logging was 5 min when in motion, with the engine on/off status being recorded to greater precision.

Due to the 5 min interval of GPS data, the exact unloading time is difficult to recognize. In this case, travel times between two GPS spots, which are the first on-premise time and the nearest on-road time, were searched on Google maps. Then the residual unloading times were calculated by subtracting $10 \mathrm{~min}$ from the travel time. 


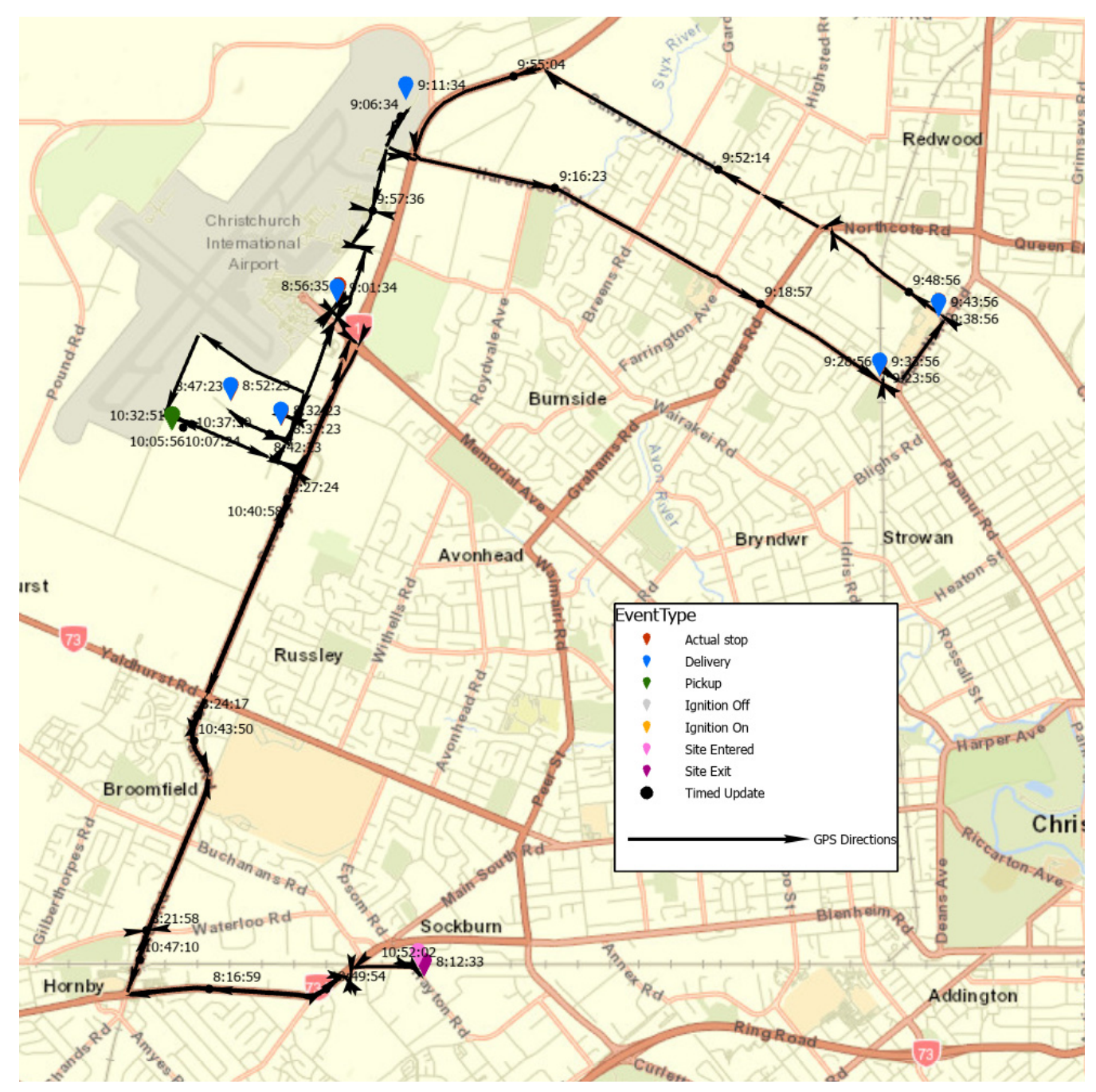

Figure 7. Truck actual route by GPS.

\subsubsection{ArcGIS Models}

ArcGIS $^{\circledR}$ is a platform of Geographic Information System (GIS). Locations are identified in ArcGIS ${ }^{\circledR}$ by addresses or XY coordinates. ArcGIS ${ }^{\circledR}$ was utilised to present customer addresses and truck locations by inputting GPS data.

Existing literature shows that GIS has been used to simulate routing problems. Therefore, several GIS models were developed and compared with DES results. Truck routes in GIS can be estimated with a specified sequence of customer addresses. Alternatively, it can find the theoretical optimal route by solving TSP. However, only the first location can be preserved by TSP in ArcGIS ${ }^{\circledR}$. There are options dedicated to trucks such as 'avoid truck restricted roads', 'driving a truck', 'tandem axle vehicles prohibited' and 'truck with trailer restriction'. These functions indicate ArcGIS pro ${ }^{\circledR}$ potentially provides robust results of routes. The truck speed is obtained from historical and live traffic data based on the traffic flow.

To compare with DES models, several GIS models were developed with the predefined sequence. To discover routes, addresses were first identified. Time measurement and distance measurement were considered to explore the least route time and the least distance routes. Options about the truck were selected, such as truck preferred routes and trucks with trailers restrictions. 


\subsubsection{Model Validation and Result Comparison}

The following Figure 8 shows ArcGIS route results with different measurements. Table 6 indicates GIS and DES results compared with GPS data. Correlations between time and distance should not be determined from this table, as the data represent different competing methods.

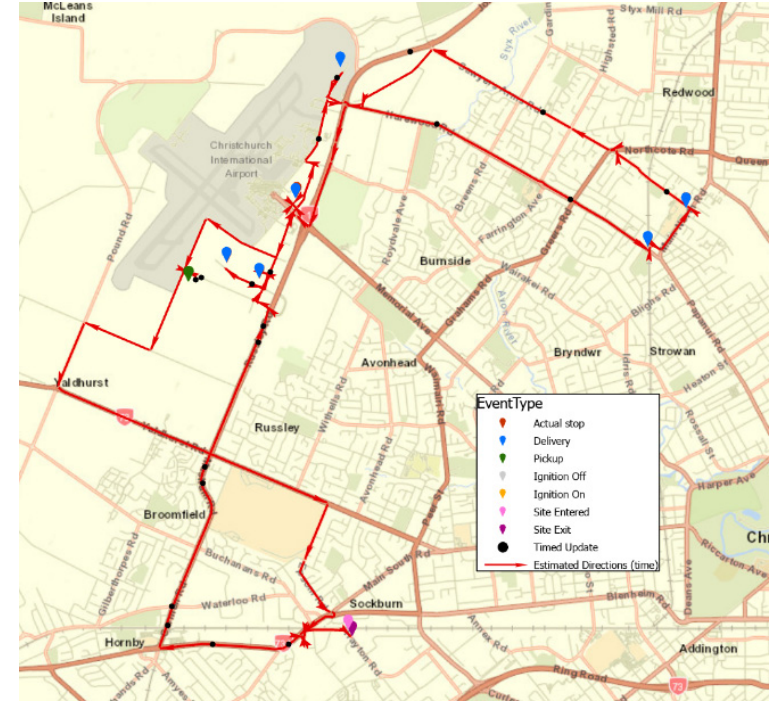

(a)

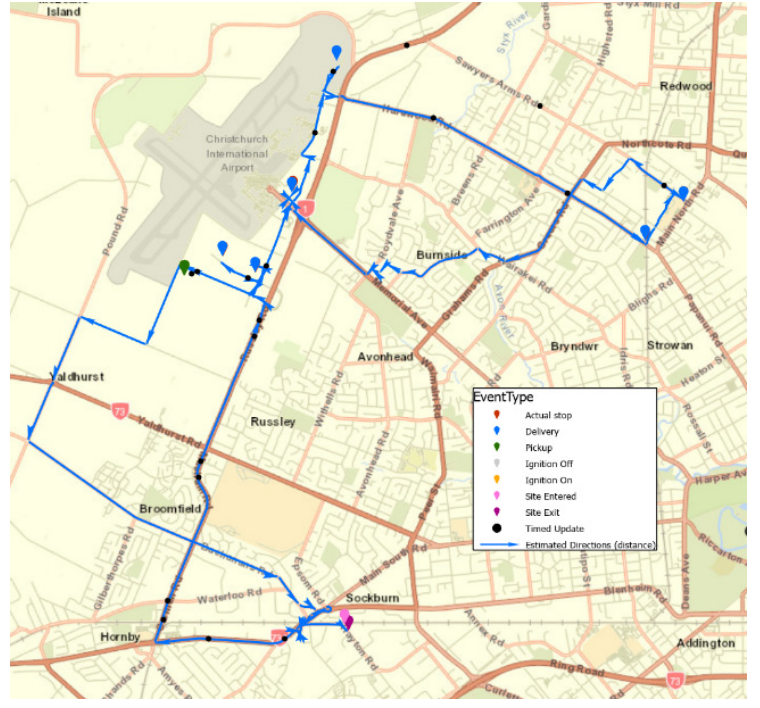

(b)

Figure 8. GIS estimated routes against GPS data (a) defined sequence by time measurement; (b) defined sequence by distance measurement.

Table 6. Results comparison.

\begin{tabular}{|c|c|c|c|c|c|c|c|}
\hline Models & $\begin{array}{c}\text { Input } \\
\text { Variables }\end{array}$ & $\begin{array}{c}\text { Key } \\
\text { Assumption }\end{array}$ & $\begin{array}{c}\text { Travel } \\
\text { Time (min) }\end{array}$ & $\begin{array}{c}\text { Travel } \\
\text { Distance } \\
(\mathbf{k m})\end{array}$ & $\begin{array}{c}\text { Output } \\
\text { Average Speed } \\
(\mathrm{km} / \mathrm{h})\end{array}$ & $\begin{array}{l}\text { Delivery } \\
\text { Sequence }\end{array}$ & Pickup \\
\hline $\begin{array}{c}\text { ArcGIS estimated } \\
\text { by time } \\
\text { measurement }\end{array}$ & $\begin{array}{l}\text { Addresses by } \\
\text { sequence }\end{array}$ & $\begin{array}{l}\text { Historical } \\
\text { traffic data }\end{array}$ & 47.018 & 39.675 & 50.630 & $\begin{array}{c}\text { Set } \\
\text { sequence }\end{array}$ & Backhaul \\
\hline $\begin{array}{l}\text { ArcGIS estimated } \\
\text { by distance } \\
\text { measurement }\end{array}$ & $\begin{array}{l}\text { Addresses by } \\
\text { sequence }\end{array}$ & $\begin{array}{l}\text { Historical } \\
\text { traffic data }\end{array}$ & 49.545 & 38.755 & 46.933 & $\begin{array}{c}\text { Set } \\
\text { sequence }\end{array}$ & Backhaul \\
\hline $\begin{array}{l}\text { Simple suburb } \\
\text { model }\end{array}$ & $\begin{array}{c}\text { Customer } \\
\text { suburb } \\
\text { clusters, } \\
\text { truck average } \\
\text { speed }\end{array}$ & $\begin{array}{l}\text { Customer } \\
\text { locations }\end{array}$ & 70.44 & 35.950 & 30.622 & $\begin{array}{c}\text { Arena } \\
\text { determined } \\
\text { sequence } \\
\text { with } \\
\text { predefined } \\
\text { priority }\end{array}$ & Backhaul \\
\hline $\begin{array}{l}\text { Intersection-based } \\
\text { model }\end{array}$ & $\begin{array}{l}\text { Customer } \\
\text { suburb } \\
\text { clusters, } \\
\text { truck average } \\
\text { speed and } \\
\text { speed factors }\end{array}$ & $\begin{array}{l}\text { Customer } \\
\text { locations }\end{array}$ & 77.97 & 36.450 & 28.049 & $\begin{array}{c}\text { Arena } \\
\text { determined } \\
\text { sequence } \\
\text { with } \\
\text { predefined } \\
\text { priority }\end{array}$ & Backhaul \\
\hline $\begin{array}{l}\text { Ground truth-GPS } \\
\text { actual }\end{array}$ & & & 73.267 & 39.200 & 32.102 & & Backhaul \\
\hline
\end{tabular}

Figures 9 and 10 display travel distance and route time for consignments from GPS data and DES results. The route was determined from discussion with dispatchers and 
drivers, not via TSP. The reason TSP was not applicable here, was because the real operations include a regular backhaul whereby the truck must take a specific last segment of the return route. In contrast, TSP requires freedom to select all segments of the route.

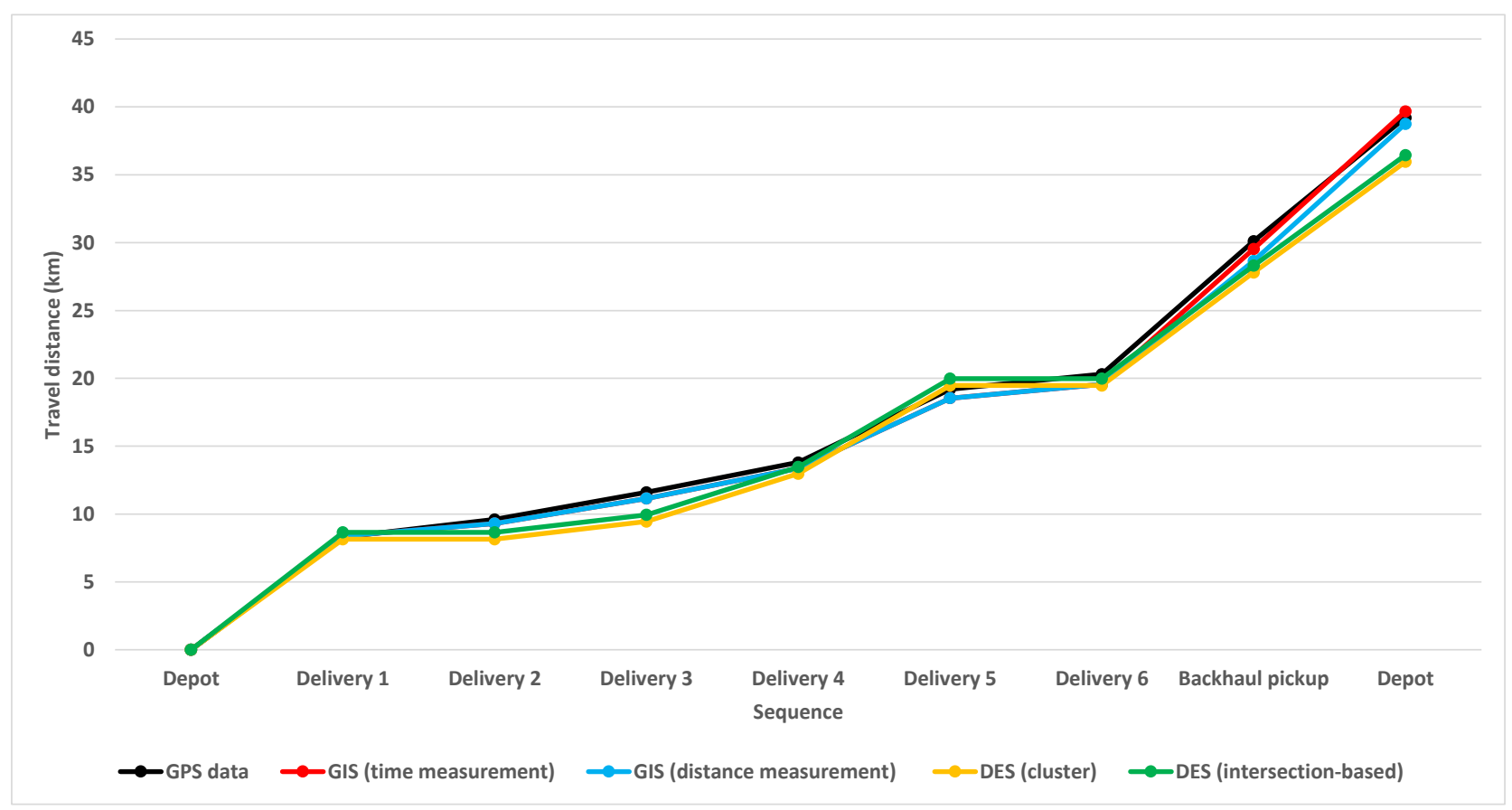

Figure 9. Travel distance for consignments from GPS data and DES results.

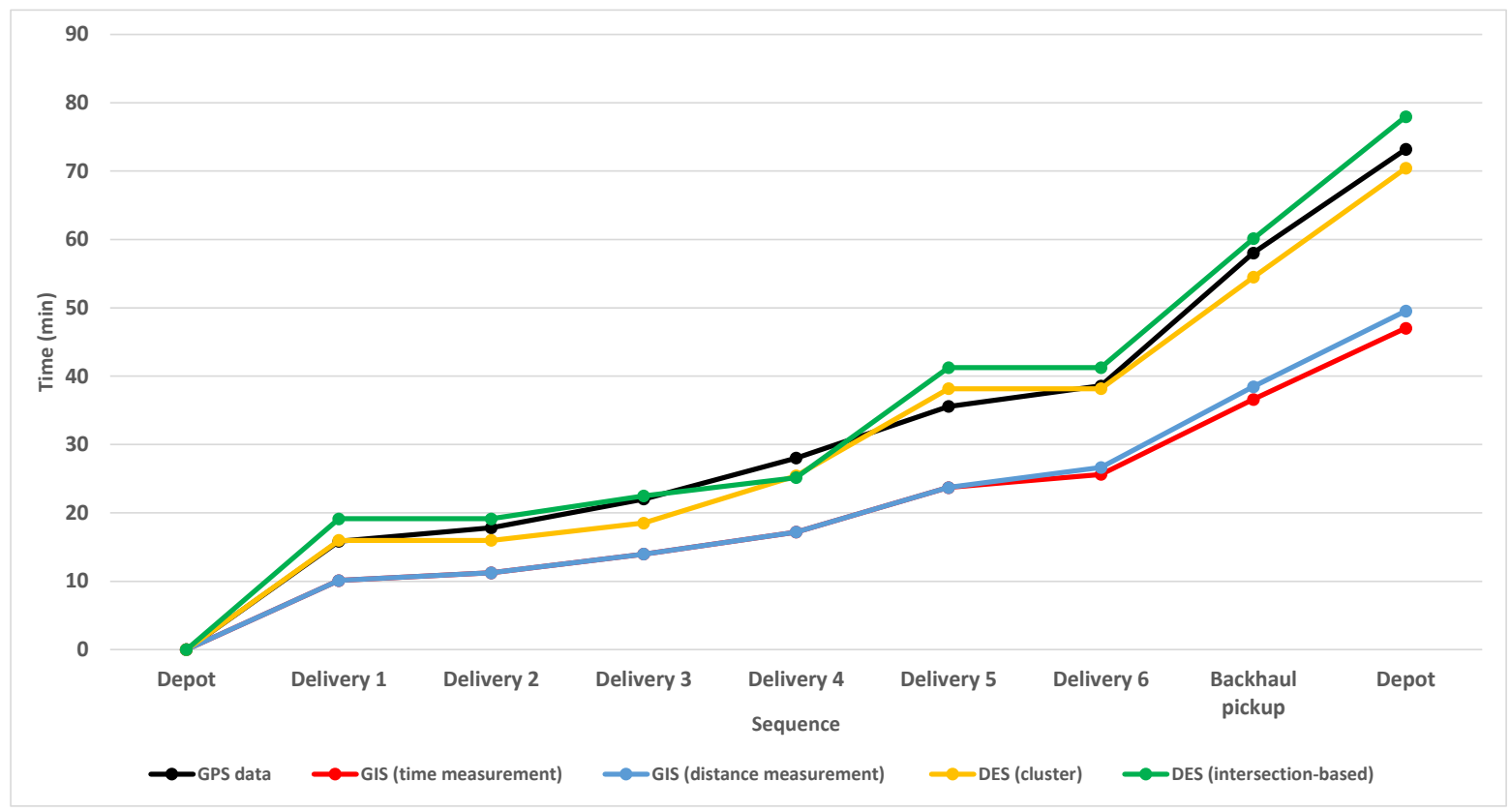

Figure 10. Route time for consignments from GPS data and DES results.

The result of the GIS estimated model by time measurement is the best for road selection and total travel distance although there are some discrepancies in some pieces of road segments. However, both these models lack consideration of truck turning and road conditions. The TSP results provided the optimal results for time or distance, although the sequence is different from the real operations in backhaul pickup. Almost all GIS models 
produce large average speeds, which are at odds with the actual travel times. The results of these models show the inherent configuration of ArcGIS pro is insufficient to generate accurate results for route time.

The DES model had the best results for travel time and the route. The route provided by DES is similar to the driver's actual route. The consignments in the same cluster have the same travel time because they were considered to be unloaded in the centre. The deviation in travel distance is caused by the simplification of clusters.

\section{Discussion}

\subsection{Advantages and Disadvantages of Logistics Simulation Models \\ 5.1.1. Pure GIS Models}

GIS is a useful tool to aid the analysis of multiple addresses and GPS data. The advantages of GIS models are the ability to process and identify massive data for network information and location, find route results by the heuristic Tabu Search technique, result visualisation [40], real-time simulation [33], and detailed traffic conditions [32]. GIS provides detailed network features for regional analysis [31]. It can run a routing simulation by inputting addresses. However, the results demonstrate that the ArcGIS model provides accurate route distance and similar routes by time measurement for trucks as long as the sequence is defined.

TSP results are theoretically optimal but they are different from the real route. As identified above, the real operations require a regular backhaul segment, which is incompatible with the TSP algorithm. Nonetheless, we applied TSP by both time and distance objective functions, with the results shown in Figure 11a,b respectively. The (a) and (b) results give a similar sequence of deliveries to the imposed sequence. However, both TSP methods place the backhaul pickup in an operationally impractical sequence. For this particular industrial operation, it is important to place the pickup last, once the truck has been emptied of deliveries, but TPS does not respect this constraint. Therefore, GIS is inconvenient for this type of delivery and pickup problem. In addition, some roads are actually not preferable or appropriate for trucks with regards to speed limits, turning directions, pedestrians, congestion and traffic lights. Results showed the time measurement is better for trucks rather than the distance measurement, a finding that is consistent with [31].

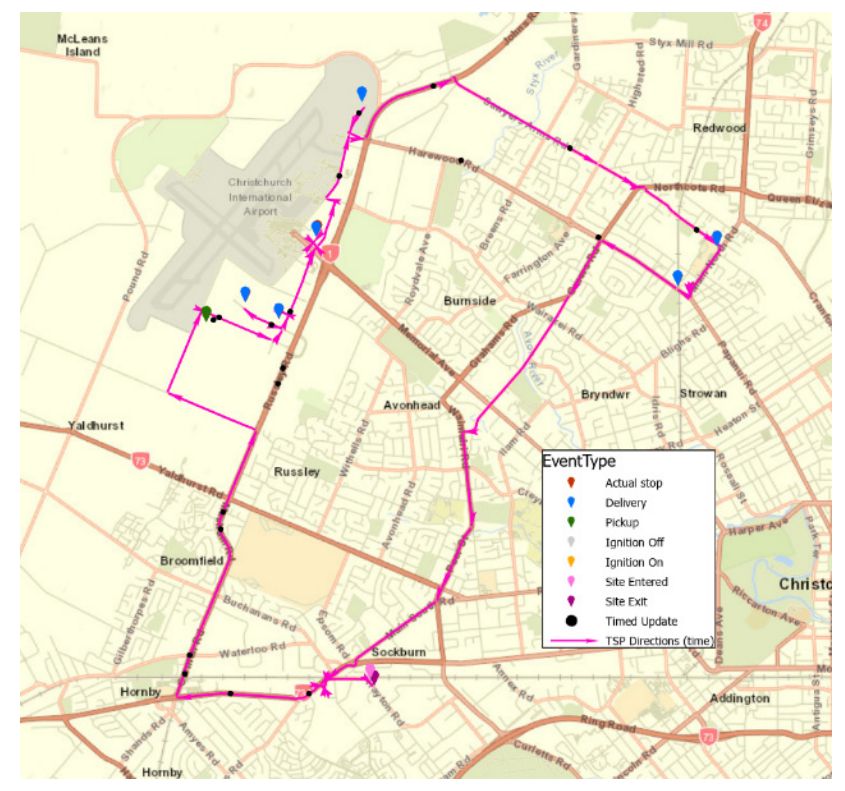

(a)

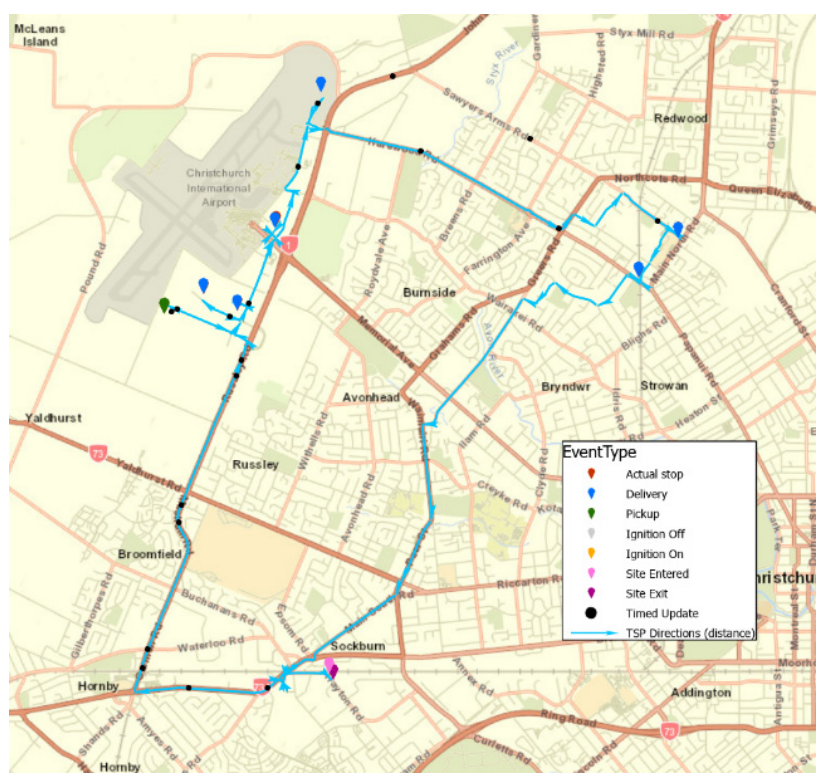

(b)

Figure 11. (a) TSP route by time measurement; (b) TSP route by distance measurement. 
Moreover, the default truck speed provided by ArcGIS is much faster than the real speed. This leads to a shorter travel time than the real travel time. It may arise from GIS ignoring low speeds, such as traffic light stops and congestion.

Disadvantages of GIS include the inability to model multiple vehicles [31], and its limitation to deterministic modelling, i.e., stochastic elements cannot be included [34]. Moreover, GIS mainly focuses on routing problems, and operational activities are difficult to include.

Consolidating our findings with those of the literature suggests that the advantages and disadvantages of GIS models, vs. combined GIS + DES models, may be summarized as in Table 7.

\subsubsection{GIS + DES Models}

The simple suburb cluster model and intersection-based model have the same operations architecture with different transport networks.

The simple suburb cluster model structure is adequate to show the sequence of consignments, and the accuracy of results are acceptable although the travel distance and route selection are deficient due to the simplification of the network. The most significant advantage of this model is the simplification greatly reduces the modelling time. Thus, this model is valuable when the modelling process is at the initial stage. E.g. to plan a network for a market. However, the network is unable to present detailed routes for real operations.

In comparison, the intersection-based model includes more road details. The network is formed by intersections so specific roads are embodied. This allows more details applied to each road with truck speeds and road directions. Therefore, the intersection-based model provided more accurate results for travel distance and travel time. The route selection is credible so the model can include driver's decisions. The disadvantage of this model is that the model construction period is more time-consuming than the simple model. The advantages and disadvantages of these two models are summarized in Table 8.

Table 7. Comparison of GIS models and GIS + DES models for PUD.

\begin{tabular}{|c|c|c|}
\hline & Advantages & Disadvantages \\
\hline $\begin{array}{l}\text { GIS models on their own } \\
\text { for PUD }\end{array}$ & $\begin{array}{l}\text { Plot customer addresses and identify } \\
\text { suburbs } \\
\text { - } \quad \text { Route with defined sequence is close to } \\
\text { the real route }\end{array}$ & $\begin{array}{l}\text { - Average truck speeds are higher than real } \\
\text { speeds. } \\
\text { - } \quad \text { Stochastic parameters cannot be simulated } \\
\text { - Some processes such as freight consolidation } \\
\text { are hard to involve } \\
\text { - It can only run one case } \\
\text { It cannot consider both delivery and pickup }\end{array}$ \\
\hline $\begin{array}{l}\text { DES models on their own } \\
\text { for PUD }\end{array}$ & $\begin{array}{l}\text { - Models complex freight operations in } \\
\text { aggregate }\end{array}$ & $\begin{array}{l}\text { Does not represent individual consignments } \\
\text { or variability resulting from customer } \\
\text { addresses } \\
\text { - Cannot determine optimal route/network }\end{array}$ \\
\hline $\begin{array}{l}\text { GIS + DES combined } \\
\text { models for PUD }\end{array}$ & $\begin{array}{l}\text { - All freight processes can be modelled } \\
\text { including freight consolidation, loading } \\
\text { and unloading } \\
\text { - } \quad \begin{array}{l}\text { Individual consignments can be } \\
\text { presented }\end{array} \\
\text { - } \quad \text { Driver's route decisions are included } \\
\text { Multiple replications can be conducted } \\
\text { with stochastic parameters }\end{array}$ & $\begin{array}{l}\text { - More data is required including GPS data } \\
\text { and consignment data } \\
\text { - } \quad \text { Need to identify customer clusters }\end{array}$ \\
\hline
\end{tabular}


Table 8. Comparison of Simple cluster suburb model and Intersection-based model.

\begin{tabular}{clll}
\hline & \multicolumn{1}{c}{ Advantages } & \multicolumn{1}{c}{ Disadvantages } \\
\hline Simple cluster suburb model & - & The modelling period is short & $\begin{array}{l}\text { Less accuracy in route details } \\
\text { One global average speed is used }\end{array}$ \\
\hline Intersection-based model & $-\quad \begin{array}{l}\text { The resulting route closely matches the } \\
\text { real selection } \\
\text { Average speeds on different types of } \\
\text { roads are applied }\end{array}$ & $\begin{array}{l}\text { The modelling period is long } \\
\text { The real traffic needs to be investigated } \\
\text { such as intersections } \\
\text { The network needs to be created based on } \\
\text { historical routes }\end{array}$ \\
\hline
\end{tabular}

\subsection{Limitations}

Although the intersection-based model can simulate the freight delivery process for the truck with satisfying results, real freight operations are more complex. The following limitations apply. First, some suburbs are ignored. These suburbs were occasionally visited by the truck. These are mainly casual customers and take up $2.75 \%$ of the annual consignment workload. Second, the truck undertakes other types of jobs. These trivial jobs include morning pickups, metro deliveries and other driver's deliveries. However, these jobs account for $10 \%$ of the whole delivery jobs, which arguably can be ignored. Third, the representative centres of clusters can be identified by other methods such as density-based clustering methods. Current errors are a few minutes in time and dozens of meters in the distance. Last, from the perspective of health and safety, the actual speed limit for urban roads may be either by $50 \mathrm{~km} / \mathrm{h}$ or $60 \mathrm{~km} / \mathrm{h}$, whereas the model simplifies this to $60 \mathrm{~km} / \mathrm{h}$.

To create a more complete logistics model, it would be necessary to include additional operational processes. One of the key operational constraints is consolidation. This is where the dispatcher at the dock allocates the incoming consignments to individual drivers. This is a complex task because of the need to consider total cargo weight and volume relative to the truck capacity. It is further complicated by the high daily variability of consignments, at least for general freight firms. The dispatcher also needs to ensure delivery windows and customer service measures are met, and this is especially so with time-critical consignments. Furthermore, any consignments not delivered on the day of arrival at the dock will accumulate to the next day, and this is problematic because of limited storage capacity on the dock - the system operates in a lean manner. Variability in driver availability is another consideration, although in practice perhaps not as severe as might be thought as such firms tend to assign drivers to overlapping suburbs, and have floater vehicles available. There is also an integration of pick-up and line-haul to consider for a more complete model.

\subsection{Implications}

The models that have been shown above are suitable for a town or region, or an area within a larger city. This raises the question of how multiple such models might be aggregated together to represent a wider logistics situation. It is possible to add more clusters for this truck and compare different scenarios. Another application is to find the best solution for allocating clusters to a fleet of trucks.

The resulting DES model can involve randomness by inputting distributions of delivery addresses, unloading time, number of pallets, freight weight and volume based on historical data. In addition, random traffic and operations delays can be included. Then the model can estimate the lead time and total distance of the consignment from the start. Moreover, the model is able to respond quickly to day-to-day operational requirements for a list of deliveries. The model may also be extended by addition of modules for consolidation module and line-haul. Consolidation refers to sorting consignments into the relevant suburb delivery routes. 
The method might also be used to analyse a new market area without historical data, which means the delivery route is unknown. In this case, if the marketing was able to provide a list of client addresses and estimated annual consignments, then the suburb clusters could be determined, and the typical tours too. Such an approach would use GIS to evaluate possible routes and the sequence based on the TSP algorithm and build the operations model by DES.

It is also possible to combine elements of both methods: historical data could be edited to reflect the expected changed business for the future year. These business changes might include the effect of plant closures, new businesses setting up, and changes in customer purchase habits (e.g., more small parcels due to online shopping).

\subsection{Opportunities for Future Research}

The intersection-based DES model has been developed and validated. Future work might conduct different scenarios, such as a change to the delivery sequence and truck types. In addition, the network could be extended to a larger area and more trucks considered.

\section{Conclusions}

This paper presents and evaluates a method to create urban PUD models. The method combines GIS and DES. Two DES models were proposed, the suburb model and the intersection-based model. In terms of travel time, the predictions of the simple suburb model $(70 \mathrm{~min})$ and intersection model $(78 \mathrm{~min})$ showed reasonable agreement with the ground truth from GPS (73 min), whereas the GIS estimated times (47-50 min) were unrealistic. The issue with GIS is that there are no representations of the slow speeds at intersections and congestion, nor the unloading times. The intersection based model was the most accurate, but its more detailed network takes more effort to construct in DES. The simple suburb model had acceptable accuracy from the perspective of the industry client, and a much simpler structure to programme into DES.

Regarding travel distances, the discrepancies were much smaller: both the simple suburb and intersection based predicted about $36 \mathrm{~km}$, compared to $39 \mathrm{~km}$ for the GPS ground truth. In this metric, the GIS models performed well, at $40 \mathrm{~km}$ and $39 \mathrm{~km}$.

We conclude that when the purpose of the simulation is to quantify the time taken, which is typically the paramount operational need, then the simple suburb model provides an exceptional balance between accuracy and ease of simulation. When the purpose is only to quantify distance travelled, then the GIS methods are the best. For those cases where both time and distance need to be simulated, as arises when considering emission metrics such as tonne-kilometre, then the intersection-based model appears to be the best. It has the advantage of being able to accommodate both time and distance within one model (rather than having to use GIS and DES), with reasonable accuracy.

With more support from GIS, the intersection-based model was able to mimic the real route and delivery sequence including a backhaul pickup. Plain GIS models were able to provide accurate route distance, but predicted unrealistic truck speeds.

This work makes several contributions to the field. It provides a method for combining GIS and DES to build freight operation models for urban PUD. This has the potential to help industry logistics practitioners better understand their current operations and experiment with different scenarios.

Author Contributions: Conceptualization, Z.L. and D.P.; methodology, Z.L. and D.P.; software, Z.L. and Z.J.; validation, Z.L. and D.P.; formal analysis, Z.L.; investigation, Z.L.; resources, Z.L. and D.P.; data curation, Z.L; writing-original draft preparation, Z.L. and D.P; writing-review and editing, Z.L., D.P., Y.Z. and Z.J.; visualization, Z.L. and D.P.; supervision, D.P. and Y.Z.; project administration, Z.L. and D.P.; funding acquisition, Z.L. and D.P. All authors have read and agreed to the published version of the manuscript.

Funding: This work was funded by Callaghan Innovation NZ, grant number MAIN1901/PROP69059-FELLOW-MAIN. 


\section{Institutional Review Board Statement: HEC 2020/65/LR-PS.}

Informed Consent Statement: Informed consent was obtained from all subjects involved in the study.

Acknowledgments: We wish to thank Mainfreight Ltd. and in particular Shaun Morrow and Trace Donaghey for generous assistance and support.

Conflicts of Interest: The authors declare no conflict of interest.

\section{References}

1. Asuncion, J.; Rendall, S.; Murray, R.; Krumdieck, S. New Zealand Intermodal Freight Network and the Potential for Mode Shifting. Ph.D. Thesis, University of Canterbury, Christchurch, New Zealand, 2012. Available online: http://hdl.handle.net/10092/8825 (accessed on 10 December 2021).

2. Kim, H.-C.; Nicholson, A.; Kusumastuti, D. Freight Transport Mode Choice and Mode Shift in New Zealand: Findings of a Revealed Preference Survey; Sustainable Logistics (Transport and Sustainability, Vol. 6); Emerald Group Publishing Limited: Bingley, UK, 2014; Volume 6, pp. 165-192.

3. Patil, G.R.; Thadoju, S.; Sahu, P.K.; Mondal, A.; Bajpai, V. Data Collection and Modeling of Restaurants' Freight Trip Generation for Indian Cities. Transp. Dev. Econ. 2021, 7, 9. [CrossRef]

4. Szander, N.; Albert, G. The Competitive Position Of Hungarian Hauling Companies In The Road Freight Transportation Sector. Bus. Logist. Mod. Manag. 2021, 21, 277-293.

5. Amaya, J.; Delgado-Lindeman, M.; Arellana, J.; Allen, J. Urban freight logistics: What do citizens perceive? Transp. Res. Part E Logist. Transp. Rev. 2021, 152, 102390. [CrossRef]

6. Hopkins, D.; McCarthy, A. Change trends in urban freight delivery: A qualitative inquiry. Geoforum 2016, 74, 158-170. [CrossRef]

7. Dulebenets, M.A. A comprehensive multi-objective optimization model for the vessel scheduling problem in liner shipping. Int. J. Prod. Econ. 2018, 196, 293-318. [CrossRef]

8. Taylor, G.D. Logistics Engineering Handbook, 1st ed.; CRC Press: Boca Raton, FL, USA, 2008. [CrossRef]

9. Ghiani, G.; Laporte, G.; Musmanno, R. Introduction to Logistics Systems Planning and Control; J. Wiley: Hoboken, NJ, USA, 2004.

10. Elbert, R.; Knigge, J.-K.; Friedrich, A. Analysis of decentral platoon planning possibilities in road freight transport using an agent-based simulation model. J. Simul. 2020, 14, 64-75. [CrossRef]

11. Silva, B.C.H.; Fernandes, I.F.C.; Goldbarg, M.C.; Goldbarg, E.F.G. Quota travelling salesman problem with passengers, incomplete ride and collection time optimization by ant-based algorithms. Comput. Oper. Res. 2020, 120. [CrossRef]

12. Marinov, M.; Viegas, J. A mesoscopic simulation modelling methodology for analyzing and evaluating freight train operations in a rail network. Simul. Model. Pract. Theory 2011, 19, 516-539. [CrossRef]

13. Robinson, S. Successful Simulation: A Practical Approach to Simulation Projects; McGraw-Hill: London, UK; New York, NY, USA, 1994.

14. Rahimi, A.M.; Dulebenets, M.A.; Mazaheri, A. Evaluation of Microsimulation Models for Roadway Segments with Different Functional Classifications in Northern Iran. Infrastructures 2021, 6, 46. [CrossRef]

15. Aliahmadi, S.Z.; Barzinpour, F.; Pishvaee, M.S. A fuzzy optimization approach to the capacitated node-routing problem for municipal solid waste collection with multiple tours: A case study. Waste Manag. Res. 2020, 38, 279-290. [CrossRef] [PubMed]

16. Salazar-Aguilar, M.A.; Langevin, A.; Laporte, G. The synchronized arc and node routing problem: Application to road marking. Comput. Oper. Res. 2013, 40, 1708-1715. [CrossRef]

17. Kumar, A. Improved Genetic Algorithm to Solve Small Scale Travelling Salesman Problem. In Proceedings of the 2020 International Conference on Intelligent Computing and Control Systems, ICICCS 2020, Madurai, India, 13-15 May 2020; pp. 516-520.

18. Agrawal, M.; Jain, V. Applying Improved Genetic Algorithm to Solve Travelling Salesman Problem. In Proceedings of the 2nd International Conference on Inventive Research in Computing Applications, ICIRCA 2020, Coimbatore, India, 15-17 July 2020; pp. 1194-1197.

19. Zbib, H.; Laporte, G. The commodity-split multi-compartment capacitated arc routing problem. Comput. Oper. Res. 2020, 122. [CrossRef]

20. Amini, A.; Tavakkoli-Moghaddam, R.; Ebrahimnejad, S. A bi-objective transportation-location arc routing problem. Transp. Lett. 2020, 12, 623-637. [CrossRef]

21. Padungwech, W.; Thompson, J.; Lewis, R. Effects of update frequencies in a dynamic capacitated arc routing problem. Networks 2020, 76, 522-538. [CrossRef]

22. Campbell, J.F.; Corberan, A.; Plana, I.; Sanchis, J.M.; Segura, P. Solving the length constrained K-drones rural postman problem. Eur. J. Oper. Res. 2021, 292, 60-72. [CrossRef]

23. Benavent, E.; Corberan, A.; Lagana, D.; Vocaturo, F. The periodic rural postman problem with irregular services on mixed graphs. Eur. J. Oper. Res. 2019, 276, 826-839. [CrossRef]

24. Afanasev, V.A.; van Bevern, R.; Tsidulko, O.Y. The Hierarchical Chinese Postman Problem: The slightest disorder makes it hard, yet disconnectedness is manageable. Oper. Res. Lett. 2021, 49, 270-277. [CrossRef]

25. Siloi, I.; Carnevali, V.; Pokharel, B.; Fornari, M.; Di Felice, R. Investigating the Chinese postman problem on a quantum annealer. Quantum Mach. Intell. 2021, 3. [CrossRef]

26. Majumder, S.; Kar, S.; Pal, T. Uncertain multi-objective Chinese postman problem. Soft Comput. 2019, 23, 11557-11572. [CrossRef] 
27. Barkaoui, M.; Gendreau, M. An adaptive evolutionary approach for real-time vehicle routing and dispatching. Comput. Oper. Res. 2013, 40, 1766-1776. [CrossRef]

28. Schmidt, L.; Gazmuri, P. Online simulation for a real-time route dispatching problem. J. Oper. Res. Soc. 2012, 63, 1492-1498. [CrossRef]

29. Bertsimas, D.; Jaillet, P.; Martin, S. Online vehicle routing: The edge of optimization in large-scale applications. Oper. Res. 2019, 67, 143-162. [CrossRef]

30. Bianchi, L.; Dorigo, M.; Gambardella, L.M.; Gutjahr, W.J. A survey on metaheuristics for stochastic combinatorial optimization. Nat. Comput. 2009, 8, 239-287. [CrossRef]

31. Keenan, P. Modelling vehicle routing in GIS. Oper. Res. 2008, 8, 201. [CrossRef]

32. Meersman, H.; Ben-Akiva, M.E.; Van De Voorde, E.; Ben-Akiva, M.E. Freight Transport Modelling; Emerald Publishing Limited: Bingley, UK, 2013.

33. Akay, A.E.; Wing, M.G.; Sivrikaya, F.; Sakar, D. A GIS-based decision support system for determining the shortest and safest route to forest fires: A case study in Mediterranean Region of Turkey. Environ. Monit. Assess. 2012, 184, 1391-1407. [CrossRef]

34. Vu, H.L.; Ng, K.T.W.; Fallah, B.; Richter, A.; Kabir, G. Interactions of residential waste composition and collection truck compartment design on GIS route optimization. Waste Manag. 2020, 102, 613-623. [CrossRef]

35. Hemidat, S.; Oelgemöller, D.; Nassour, A.; Nelles, M. Evaluation of Key Indicators of Waste Collection Using GIS Techniques as a Planning and Control Tool for Route Optimization. Waste Biomass Valorization 2017, 8, 1533-1554. [CrossRef]

36. Jwad, Z.A.; Hasson, S.T. An Optimization Approach for Waste Collection Routes Based on GIS in Hillah-Iraq. In Proceedings of the 2018 International Conference on Advanced Science and Engineering, ICOASE 2018, Duhok, Kurdistan Region, Iraq, 9-11 October 2018; pp. 60-63.

37. Vu, H.L.; Bolingbroke, D.; Ng, K.T.W.; Fallah, B. Assessment of waste characteristics and their impact on GIS vehicle collection route optimization using ANN waste forecasts. Waste Manag. 2019, 88, 118-130. [CrossRef]

38. Dao-Tuan, A.; Nguyen-Thi-Ngoc, A.; Nguyen-Trong, K.; Bui-Tuan, A.; Dinh-Thi-Hai, V. Optimizing vehicle routing with path and carbon dioxide emission for municipal solid waste collection in Ha Giang, Vietnam. In Proceedings of the 3rd International Conference on Industrial Networksand Intelligent Systems, INISCOM 2017, Ho Chi Minh City, Vietnam, 4 September 2017; pp. 212-227.

39. Pamučar, D.; Gigović, L.; Ćirović, G.; Regodić, M. Transport spatial model for the definition of green routes for city logistics centers. Environ. Impact Assess. Rev. 2016, 56, 72-87. [CrossRef]

40. Zsigraiova, Z.; Semiao, V.; Beijoco, F. Operation costs and pollutant emissions reduction by definition of new collection scheduling and optimization of MSW collection routes using GIS. The case study of Barreiro, Portugal. Waste Manag. 2013, 33, 793-806. [CrossRef]

41. Couclelis, H. The Certainty of Uncertainty: GIS and the Limits of Geographic Knowledge. Trans. GIS 2003, 7, 165-175. [CrossRef]

42. Mommens, K.; Lebeau, P.; Verlinde, S.; van Lier, T.; Macharis, C. Evaluating the impact of off-hour deliveries: An application of the TRansport Agent-BAsed model. Transp. Res. Part D Transp. Environ. 2018, 62, 102-111. [CrossRef]

43. Lu, S.; Xin, B.; Zhang, H.; Chen, J. Agent-based Self-organized Constructive Heuristics for Travelling Salesman Problem. In Proceedings of the 2020 59th IEEE Conference on Decision and Control (CDC), Jeju, Korea, 14-18 December 2020; pp. 1164-1169. [CrossRef]

44. Blamah, N.V.; Oluyinka, A.A.; Wajiga, G.; Baha, Y.B. MAPSOFT: A Multi-Agent based Particle Swarm Optimization Framework for Travelling Salesman Problem. J. Intell. Syst. 2021, 30, 413-428. [CrossRef]

45. Viana, J.; Ziener, V.M.; Holhjem, M.S.; Ponton, I.G.; Thogersen, L.J.; Simonsen, T.B. Optimizing home hospital health service delivery in norway using a combined geographical information system, agent based, discrete event simulation model. In Proceedings of the 2017 Winter Simulation Conference, WSC 2017, Las Vegas, NV, USA, 3-6 December 2017; pp. 1658-1669.

46. Kogler, C.; Rauch, P. Discrete event simulation of multimodal and unimodal transportation in the wood supply chain: A literature review. Silva Fenn. 2018, 52, 9984. [CrossRef]

47. Abbott, D.; Marinov, M.V. An event based simulation model to evaluate the design of a rail interchange yard, which provides service to high speed and conventional railways. Simul. Model. Pract. Theory 2015, 52, 15-39. [CrossRef]

48. Motraghi, A.; Marinov, M.V. Analysis of urban freight by rail using event based simulation. Simul. Model. Pract. Theory 2012, 25, 73-89. [CrossRef]

49. Wu, B.; Liu, Z.; Liu, B. The Model and Simulation of Utilization Optimization of Railway Passenger Waiting Compartment Based on Arena. In Proceedings of the 2013 International Conference on Computational and Information Sciences, Shiyang, China, 21-23 June 2013; pp. 1216-1219.

50. Zhao, Y.; Ioannou, P.A.; Dessouky, M.M. Dynamic Multimodal Freight Routing Using a Co-Simulation Optimization Approach. IEEE Trans. Intell. Transp. Syst. 2018, 20, 2657-2667. [CrossRef]

51. Li, L.; Qiu, M.; Wu, B.; Wang, X. Simulation Research on Road Transport in Container Port Based on Arena. In Proceedings of the ICLEM 2010: ICLEM 2010: Logistics For Sustained Economic Development: Infrastructure, Information, Integration, Chengdu, China, 8-10 October 2010; pp. 1880-1888. [CrossRef]

52. Jaoua, A.; Riopel, D.; Gamache, M. A simulation framework for real-time fleet management in internal transport systems. Simul. Model. Pract. Theory 2012, 21, 78-90. [CrossRef] 
53. Wu, W.; Shen, L.; Ji, X.; Jin, W. Analysis of freeway service patrol with discrete event-based simulation. Simul. Model. Pract. Theory 2014, 47, 141-151. [CrossRef]

54. Sun, L.; Sun, Y.; Zheng, W. The stochastic and dynamic vehicle routing problem with crowdshipping. In Proceedings of the 17th COTA International Conference of Transportation Professionals: Transportation Reform and Change-Equity, Inclusiveness, Sharing, and Innovation, CICTP 2017, Shanghai, China, 7-9 July 2017; pp. 1500-1510.

55. Herazo-Padilla, N.; Montoya-Torres, J.R.; Nieto Isaza, S.; Alvarado-Valencia, J. Simulation-optimization approach for the stochastic location-routing problem. J. Simul. 2015, 9, 296-311. [CrossRef]

56. Mayer, T.; Uhlig, T.; Rose, O. An open-source discrete event simulator for rich vehicle routing problems. In Proceedings of the 19th IEEE International Conference on Intelligent Transportation Systems, ITSC 2016, Rio de Janeiro, Brazil, 1-4 November 2016; pp. 1305-1310.

57. Outalha, A.; Lakhal, Y.; Baghli, F.Z.; Kzaiber, F. The efficiency of discrete event systems for the general pickup and delivery problem with electric vehicles. In Proceedings of the 3rd International Conference of Computer Science and Renewable Energies, ICCSRE 2020, Agadir, Morocco, 22-24 December 2020.

58. Sun, Z.; Guan, Z. Vehicle routing problem based on object-oriented discrete event simulation. In Proceedings of the 2nd IEEE International Conference on Advanced Computer Control, ICACC, Shenyang, China, 27-29 March 2010; pp. 638-643. 